\title{
A Study of the Fragility of Microfinance Institutions in China:Take Zhejiang Province As an Example
}

\author{
Lan Dongfang, Li Jiming*, Zhu Linxue, Gan Hongyan, Du Jinling \\ Business school \\ Zhejiang University City College \\ Hangzhou, China
}

\begin{abstract}
As a way of financing the gaps in bank system, microfinance has been favored by many micro-enterprises and low-income people in China. However, neither the international nor the domestic has given a clear definition. On the theoretical level, the development of foreign microfinance industry is relatively mature and its research is in-depth. The introduction of microfinance in China is relatively late, and the development time is less than ten years. The rapid shrinking of the microfinance industry and industry funding crisis has proven the need for correct theoretical guidance. From the perspective of financial fragility, this paper argues that the fragility of microfinance is similar to the banking sector based on existing domestic and foreign literature, and analyzes the current level of fragility in Zhejiang Province based on empirical research, then makes targeted recommendations from the perspectives of company and government.
\end{abstract}

Keywords-Microcredit; Financial bank; Fragility; MFIs

\section{INTRODUCTION}

Microcredit originated in Bangladesh and started with a pilot microfinance poverty alleviation experiment conducted by Prof. Muhammad Yunus.

In China, microcredit is favored by low-income rural populations and micro-enterprises because of its simple procedures and rapid arrival rate. China has also introduced relevant policies to encourage the development of microfinance.

Since the pilot project of small loan companies was started in Zhejiang Province in 2008, microfinance has played an important role in the construction of micro enterprises and "three rural issues". By the end of 2017, there are 326 province's small-credit institutions and 3418 employees, 57.458 billion yuan of paid-in capital and 66.824 billion yuan of loan balance. The annual interest rate for loans in the province declined, many companies adhering to online finance, innovating distinctive operating modes have achieved success.

It is noteworthy that the non-performing loan ratio in the small loan industry in Zhejiang Province is still at a relatively high level. Due to the cancellation of the pre-tax provision policy, the provision coverage ratio has fallen by a large margin and the development of the small loan industry needs more in-depth theoretical system support.

The concept of financial fragility was proposed in the early 1980s. Its main purpose is to explain the phenomena such as the financial crisis that cannot be explained from an external macroeconomic perspective.

In 1982, Hyman. P. Minshy first made a systematic explanation of financial vulnerability in his article of "Inherent Vulnerability in the Financial System." He believes that the inherent vulnerability of finance is the nature of the financial industry and is determined by the characteristics of the industry in which finance is highly indebted. This also formed the definition of narrow financial fragility today. The author classifies borrowers into three categories: offsetting, investment, and Ponzi. In the early stage of economic development, the borrowers are mainly in the form of offsetting. The uncertainties of new-type enterprises about the future production and the relatively small scale of enterprises make the financing demand of the enterprises lower. With the development of the economy, the entity companies began to precipitate and develop and the scale has also been expanded, but this also requires more working capital. Enterprises increase their own equity ratio to promote financing. In terms of banks, they can adjust interest rates, increase lending and regulatory system to promote the development of the market. However, the forward cash flow is uncertain. Once the actual income has a negative deviation from the expected level, the number of speculative borrowers and ponzi borrowers in the banking system will suddenly increase, which makes the entire credit more vulnerable and in an unstable state. At the same time, if some adverse exogenous shocks (rising interest rates, credit crunch, etc.) cut off financing channels of speculative borrowers and Ponzi borrowers, it will immediately cause a large number of loan defaults, even in severe cases. financial crisis.

David and Mosley's research on 13 microfinance institutions in 7 countries shows that microcredit has a greater impact on the average income of customers who are above the poverty line than those who are below the poverty line.

The Research by Navajas et al. about Bolivian microfinance institutions shows that the majority microfinance institutions clients are near the poverty line, and these customers do not represent the poorest people. This shows that the role of microfinance in poverty alleviation is limited and that it usually only works at a certain level of poverty.

Li Jiming is the corresponding author. 


\section{LITERATURE REVIEW}

Wu Zhiwen (2002) conducted a specific analysis about the extent of China's financial vulnerability from 1991 to 2000. Finally, he proposed some countermeasures to reduce or eliminate the existing financial vulnerabilities .The literature shows that, in a broad sense, financial fragility is a form of the continuous accumulation of risks, and it represents higher financial risks. Specifically speaking, China's financial system vulnerability can be divided into four parts: (1) vulnerability of financial market subsystems; (2) vulnerability of banking subsystems; (3) vulnerability of financial monitoring subsystems; 4) The vulnerability of the macroeconomic environment subsystem. We can see that the weight of financial vulnerability $40 \%$ is given to the banking subsystem, and the main indicators of this are non-performing loan ratio, capital adequacy ratio, return on assets, and asset-liability ratio. In addition, the literature points out that the famous CAMEL indicator system and "timely corrective measures" is one of the effective measures to prevent and resolve financial fragility. Timely corrective measures are based on the calculation of bank's own capital ratio to identify the degree of bank vulnerability, which have been playing a good role in the longterm practice.

Zhang Dazhong (2015), after analyzing the status quo of the development of the 16 major commercial banks in China, comprehensively evaluates the vulnerability of the banking system from the microscopic perspective, and observes the trend of the BFI index over the years. He finds that the overall vulnerability has a tendency of fluctuation. The author also uses the entropy method from the micro perspective to compare the vulnerability of these 16 listed companies. Model finally chose 3 kinds of factors as the interpretation of the village Banks vulnerability and these three factors were renamed as regional economic factors, competitiveness factors, and asset quality factors according to the nature of their respective indicators. Then the factor score is calculating by the regression and the proportion of the variance contribution rate of each factor is regarded as the weight to sum up.

Fu Ling (2013) believes that the fragility of China's rural banks lies mainly in the dual structure of rural financial markets, and that customer's rural financial markets have highrisk characteristics. The author through factor analysis explores the causes of village bank's vulnerability and divides the indicators into three categories: external economic indicators, rural financial dual-structure indicators, and rural banks' internal robustness indicators.

Zhang Xiu (2016), according to the understanding of systematic financial risks, measures systematic financial risks, and responds to the logical structure of systemic financial risks.

Li Shu conducts field surveys and questionnaire surveys on the status quo of the development of small loan companies in Zhejiang Province. From small-loans companies' financing status, loan status, financial status, risk control status, and operating capability status, they conduct small-scale investigations on Zhejiang Province and make the descriptive statistics to analyze the development status and identify the existing problems.
Zhang Yunyan (2013) selects 16 indicators such as age, education level and labor force population from the four aspects: individual characteristics, economic structure, loan shape, and default recognition, and establishes a credit evaluation system for farmers. Her research shows that the income of rural households is inversely proportional to the risk of default.

Yang Yu-Yan (2016) believes that due to the lack of views and understanding, there are serious deviations between the development of some small loan companies and their initial intentions. Microfinance companies must strengthen their risk management system.

$\mathrm{Xu}$ Yan (2010) analyzes the vulnerability characteristics of China's financial system. Because the banking system is the main body of China's finance, the main cause for China's fragility is the non-performing assets accumulated by commercial banks.

Shen Bing and Li Xiaoling (2006) analyze the fragility of rural finance from the four aspects: rural financial institutions, institutional arrangements of rural financial institutions, and the credit environment of rural financial institutions, and put forward corresponding policy recommendations.

Zhang Man (2009) explores the fragility of the new rural banking industry from the perspective of financial ecology. In addition to the inherent vulnerability of the banking sector which has high debt management, the deterioration of the external financial ecological environment also exacerbated its vulnerability. This is mainly reflected in the backwardness of the rural economy, the high risk of default by rural households, the imperfect agricultural finance, the lack of risk diversification mechanisms, the low level of cultural education of rural labor force, and the low efficiency of government intervention. We believe that the fragility of microfinance can be approximately replaced by the bank's fragility, which is related to the mode of operation of microfinance institutions. Bank's fragility is an extension of financial fragility. Mr. Zhang Yuan defines the fragility of China's banking industry as: "The banking industry's fragility is the nature of a financial system that increases and transmits the risk of the real economy." According to the bank's fragility theory, we can summarize the fragility of the microfinance industry into the following attributes:

(1) Endogenous. The microfinance industry is similar to the banking industry because it has similar loan mechanisms and credit information systems. The differences are that the microcredit procedures are relatively simple and the loan amount is controlled at around 10-30 million yuan. In China, all indicators of the microfinance industry should be based on the banking industry, because of the similar operating mechanism and fragility. (2) Self-enhancement. Similar to the banking industry, there is also a mutual competition and mutual learning relationship among the microfinance industry, which also contribute self-development. It will also increase the fragility of microfinance. (3) Directivity. The accumulation of banking vulnerabilities has triggered banking crisis, so does microfinance industry. The financial events of Gramemi Bank pushed microfinance to the wave of public opinion. Rabin, "microfinance capital," also broke out a major debt crisis. It is 
unclear whether this type of crisis-caused economic crisis is cyclical, but it is certain that without a more detailed analysis of the fragility of microfinance like banks, it can be a time bomb rather than tools to promote the development of grassroots groups.

\section{THEORETICAL ANALYSIS}

Microcredit is a sub-concept of inclusive finance. With the continuous development of the construction of new socialist villages in recent years, microfinance has been favored by more and more micro-enterprises and low-income groups. In China, microfinance institutions can be divided into six categories: microfinance companies, community banks, rural credit cooperatives, township banks, financing guarantee companies and commercial banks. Among them, microfinance companies with its private capital holding and information acquisition advantages are the most prominent. However, it should be pointed out that all non-bank institutions have the problem of insufficient follow-up funds, which is one of the important reasons that hinder their development.

\section{METHODS}

\section{A. Data sources}

In 2016, Zhejiang has opened 341 small lending companies (including 45 in Ningbo), which has decreased by three compared to the same period of last year; registered capital totaled 651.35 yuan, a decrease of $4.96 \%$ year-on-year. The financing balance was 5.072 billion yuan (including bank financing 3.507 billion yuan), a year-on-year decrease of $20.68 \%$; the amount of loanable funds was 77.698 billion yuan, a year-on-year decrease of $7.07 \%$; the loan balance was 72.55 billion yuan, a year-on-year decrease of $9.18 \%$; the average household loan balance was 111.04 million Yuan, an increase of $1.75 \%$ year-on-year; the average annual loan interest rate was $13.78 \%$, a year-on-year decrease of $11.15 \%$.

In 2016, a new micro-credit company was established in Zhejiang, four were cancelled in the pilot, and none company has capital increased. The province had a total of 56 capital reductions, and the total amount of funds reduced was 3.788 billion yuan. Zhejiang Province has three micro-credit companies with "National Excellent Business Models", relying on their own geographical advantages and government support, the development of the micro credit industry in Zhejiang is advancing by leaps and bounds. The China Micro-Credit Companies Association gave a summary of four points to Zhejiang after its investigation in 2017: (1) The micro-credit company in Zhejiang has made great contributions to the local real economy. (2) The development of the micro-credit company in Zhejiang is at the forefront of the country. (3) The risk control ability of Zhejiang micro-credit companies is relatively strong. (4) The exploration of the micro-credit company in Zhejiang has taken the lead in the country.

It can be seen that in the development of the past ten years, the microfinance industry in Zhejiang has rapidly developed from the very beginning to the current survival of the fittest, the industry scale has shrunk, the scale of loanable funds has decreased substantially, and non-performing loans have risen cumulatively. The non-performing rate continues to rise, and the fragility of microfinance are constantly emerging.

\section{B. Data Analysis}

According to Wu Zhiwen's research, we quantifies the vulnerability of microfinance into four indicators: nonperforming loan ratio (NPL), provision coverage ratio (PC), return on assets (ROA), and asset-liability ratio (AL). We use the excellent enterprise of micro-credit company in Zhejiang as a research object, there are two reasons to choose Zuoli: (1) Zuoli is the largest micro-credit company in Zhejiang, and its data is representative. (2) Zuoli is the leader in the industry. Tang Xinmin, the general manager of Zhejiang micro-credit, believes that micro-credit in Zhejiang has entered the period of survival of the fittest and the second-level differentiation will become more apparent, and so does the gap between companies.

The data for the past three years are as follows:

TABLE I. INDICATORS

\begin{tabular}{|c|c|c|c|c|}
\hline & NPL & PC & ROA & AL \\
\hline 2017.06 .30 & $1.5 \%$ & $268 \%$ & $9.9 \%$ & $32.11 \%$ \\
\hline 2016.12 .31 & $1.4 \%$ & $305 \%$ & $10.67 \%$ & $27.97 \%$ \\
\hline 2016.06 .30 & $2.0 \%$ & $225.8 \%$ & $10.96 \%$ & $26.99 \%$ \\
\hline 2015.12 .31 & $2.4 \%$ & $208 \%$ & $10.52 \%$ & $\mathbf{8 . 3 4 \%}$ \\
\hline 2014.12 .31 & $1.3 \%$ & $306.3 \%$ & $9.62 \%$ & $17.54 \%$ \\
\hline
\end{tabular}

According to the latest information released by the China Banking Regulatory Commission on the "Regulations on Adjustment of Regulatory Requirements for Loan Losses of Commercial Banks," we have divided the indicators into numerical ranges. The specific data are as follows:

TABLE II. INTERVAL

\begin{tabular}{|c|c|c|c|c|}
\hline NPL & $<1.4$ & $1.4 \sim 1.8$ & $1.8 \sim 2.2$ & $>2.2$ \\
\hline PC & $>210$ & $180 \sim 210$ & $150 \sim 180$ & $<150$ \\
\hline ROA & $>15$ & $10 \sim 15$ & $5 \sim 10$ & $<5$ \\
\hline AL & $<45$ & $45 \sim 65$ & $65 \sim 85$ & $>85$ \\
\hline $\begin{array}{c}\text { Numerical } \\
\text { interval }\end{array}$ & $0 \sim 20$ & $\mathbf{2 0} \sim 50$ & $50 \sim 80$ & $80 \sim 100$ \\
\hline Fragility & Safe & Normal & Attention & Danger \\
\hline
\end{tabular}

According to this indicator, we evaluate zuoli's works in the past three years, and the indicators of fragility are as follows:

TABLE III. FRAGILITY IN ZHEJIANG

\begin{tabular}{|c|c|c|c|c|c|}
\hline & $\begin{array}{c}2017.06 . \\
30\end{array}$ & $\begin{array}{c}2016.12 . \\
31\end{array}$ & $\begin{array}{c}2016.06 . \\
30\end{array}$ & $\begin{array}{c}2015.12 . \\
31\end{array}$ & $\begin{array}{c}2014.12 . \\
31\end{array}$ \\
\hline Fragility & 23.57 & 16.53 & 34.13 & 61.67 & 29.17 \\
\hline
\end{tabular}

From the results of quantitative processing, it can be seen that in the past three years, the vulnerability of Zuoli has shown a trend of rising first and then decreasing, but in 2017, the vulnerability has increased significantly again. Besides, Zuoli's vulnerability score is up to 61.67. In 2015, the credit of various 
banks was gradually tightened. The financing problem of SMEs was enlarged. Many small and micro enterprises were in financial difficulties. This indirectly affected micro-credit companies, resulting in a significant increase in overdue rates and non-performing loan ratios. In addition, the improper behavior of shareholders has a far-reaching impact. Cases of misappropriation of funds are not uncommon. This will not only create credit risk, but serious cases will also make microcredit companies run into trouble and eventually go bankrupt.

\section{FRAGILITY}

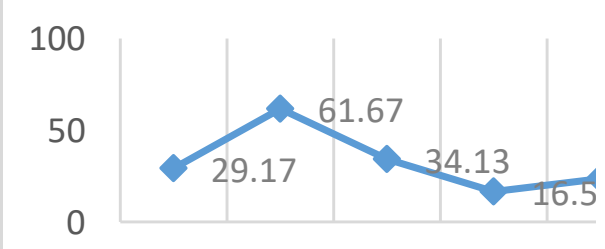

Fig. 1 Vulnerability of Zuoli MFI in the past three years

\section{CONCLUSIONS AND SUGGESTIONS}

\section{A. Conclusions}

Based on the studies above, we found that the average vulnerability of Zuoli micro-credit was relatively low and remained within the safety range in 2014, 2016, and 2017.In 2015, Bad loan rate crisis broke out: the 15 shanshui SCP001 debt default event, the 12 shun tian debt may be suspended for appearing on the market, 11 yun wei debt was declined in rating, things happened one after another, changing their state.

Many events show that our country's credit risk is gradually rising, in 2015, China's non-performing loan rate has reached $1.59 \%$, as companies lose leverage and credit defaults gradually increase, the entire credit market is in a state of high pressure. With the adjustment of credit policies by all banks in 2016, the overall risk of the market gradually decreased. The study on non-performing loan collection measures also increased significantly in the same year and credit institutions also passed the peak of non-performing loans. However, the crisis of non-performing loans has not yet passed. The outlook for the credit market is still not optimistic.

\section{B. Suggestions}

The pilot program for microfinance in China has been carried out in Zhejiang for nine years. In the past nine years, Zhejiang Micro-credit had a clear positioning for supporting agriculture and supporting agriculture. Adhere to the principle of "small-scale dispersion" and give full play to the flexibility of small-loan companies to provide differentiated financial services for the real economy.

(1) Improve the regulatory framework and perfect risk prevention and control. Zhejiang has been doing a good job in risk prevention and control. It not only established a regulatory system at the first time, but also formulated the "Zhejiang Micro-credit Company Risk
Classification Guidelines" to further standardize and unify risk classification standards. It is precisely because of outstanding prevention and control work in Zhejiang that the vulnerability of micro-credit is relatively low and is in a safe range.

(2) Broaden financing channels. The single financing channel is one of the core problems of microfinance. As the origin of the network economy, Zhejiang should make good use of its own advantages and promote the organic integration of micro-credit companies with emerging industries such as online credit and P2P companies to create a new economy.

(3) Implement preferential policies and communicate more with companies. Since microfinance companies are not suitable for preferential tax policies, the overall tax burden is close to $30 \%$. Because of their particularity, micro-credit companies are not suitable for preferential policies in rural areas such as village and township banks, nor do they apply to preferential policies of commercial banks.

\section{Research limitation}

This empirical study also has many deficiencies: (1) The analysis is not perfect. We only use one typical company as a representative. And this is because the microfinance company's financial report data is too difficult to obtain. (2) The scoring results are based on scores obtained by various teachers in the college and related personnel of a small number of microfinance companies. The credibility of the data is not high enough.

\section{REFERENCES}

[1] G. Kaminsky and Reinhart, “ The twin crises : the causes of banking and balance-of-paym ents problems", International Finance Discussion Paper No. 544, Board of Governors of The Federal Reserve System. March, 1996.

[2] Yang Yuyan, "Sustainable development of small loan companies: customer orientation, credit technology, community relations and business development models - based on the practice of 10 years of small loan industry", Southwest Finance, vol. 09, pp. 62-65, 2016. (In Chinese)

[3] Zhang Yunyan, Wang Leiling, and Luo Jianchao, "Influencing factors of credit risk of county-level rural cooperative financial institutions", Journal of Northwest A\&F University (Social Science Edition), vol. 13(02), pp.51-57, 2013. (In Chinese)

[4] Xu Yan, "Analysis of financial fragility of china's financial system", Productivity Research, vol.04, pp. 75-77, 2010. (In Chinese)

[5] Wu Zhiwen, "Analysis of China's financial vulnerability", Economic Science, vol.03, pp. 5-13, 2002. (In Chinese)

[6] Aye H P, Nakamori Y., Constructing an access system for unbanked in myanmar to a microfinance institution, Journal of Systems Science and Systems Engineering, , vol.24(2), pp. 229-257, 2015.

[7] Montgomery H, Weiss J., "Modalities of microfinance delivery in Asia and Latin America: lessons for China", China \& World Economy, vol. 14(1), pp. 30-43, 2006,.

[8] Noreen S., "Role of microfinance in empowerment of female population of bahawalpur district", International Proceedings of Economics Development \& Research, 2011. 